\title{
ATRIBUTOS DO SOLO E ACÚMULO DE CARBONO NA INTEGRAÇÃO LAVOURA-PECUÁRIA EM SISTEMA PLANTIO DIRETO
}

\author{
Nídia Raquel Costa ${ }^{(1)}$, Marcelo Andreotti ${ }^{(2) *}$, Keny Samejima Mascarenhas Lopes ${ }^{(3)}$, Kazuo \\ Leonardo Yokobatake ${ }^{(3)}$, João Paulo Ferreira ${ }^{(4)}$, Cristiano Magalhães Pariz ${ }^{(5)}$, Carolina dos \\ Santos Batista Bonini ${ }^{(6)}$ e Vanessa Zirondi Longhini ${ }^{(5)}$
}

(1) Universidade Estadual Paulista, Faculdade de Ciências Agronômicas, Departamento de Produção e Melhoramento Vegetal, Campus de Botucatu, Botucatu, São Paulo, Brasil.

(2) Universidade Estadual Paulista, Faculdade de Engenharia, Departamento de Fitossanidade, Engenharia Rural e Solos, Campus de Ilha Solteira, Ilha Solteira, São Paulo, Brasil.

(3) Universidade Estadual Paulista, Faculdade de Engenharia, Programa de Pós-graduação em Zootecnia, Campus de Ilha Solteira, Ilha Solteira, São Paulo, Brasil.

(4) Universidade Estadual Paulista, Faculdade de Engenharia, Programa de Pós-graduação em Agronomia - Sistemas de Produção, Campus de Ilha Solteira, Ilha Solteira, São Paulo, Brasil.

(5) Universidade Estadual Paulista, Faculdade de Medicina Veterinária e Zootecnia, Programa de Pós-graduação em Zootecnia, Botucatu, São Paulo, Brasil.

(6) Universidade Estadual Paulista, Campus de Dracena, Dracena, São Paulo, Brasil.

* Autor correspondente.

E-mail: dreotti@agr.feis.unesp.br

\section{RESUMO}

Em sistemas de produção como a integração lavoura-pecuária (ILP) em sistema plantio direto (SPD) têm sido observadas melhorias nos atributos químicos, físicos e biológicos do solo. Sendo assim, objetivou-se avaliar as alterações nos atributos químicos e físicos do solo e o acúmulo de carbono (C) num Latossolo Vermelho distrófico típico argiloso utilizado em sistema de ILP em SPD com irrigação, no Cerrado. O delineamento experimental utilizado foi de blocos casualizados, com quatro repetições. Os tratamentos foram dispostos em parcelas subdivididas no tempo, e as parcelas experimentais foram compostas pelas culturas do milho e do sorgo forrageiro cultivadas exclusivamente ou consorciadas com as espécies forrageiras Urochloa brizantha cv. Xaraés e Megathyrsus maximum cv. Tanzânia para ensilagem; pelas espécies forrageiras no período de entressafra; e pela cultura da soja em sucessão. Foram 


\begin{abstract}
realizadas durante a condução dos experimentos, além da análise com a caracterização inicial do solo, cinco avaliações (épocas) dos atributos químicos e físicos do solo ao final de cada ciclo produtivo durante os anos agrícolas 2010/2011, 2011/2012 e 2012/2013. Os sistemas de produção na ILP em SPD, mesmo com alta exportação de nutrientes e tráfego de máquinas, foram eficientes para manutenção e melhoria da fertilidade e dos estoques de $\mathrm{C}$ do solo. Ao longo de três anos, os sistemas de ILP promoveram redução da compactação do solo pelo efeito positivo de incremento da macroporosidade e porosidade total e diminuição da resistência mecânica à penetração e densidade do solo, nas camadas de 0-0,10 e 0,10-0,20 m.
\end{abstract}

Palavras-chave: matéria orgânica, capacidade de troca catiônica, resistência mecânica à penetração, densidade do solo, estoque de carbono.

\title{
ABSTRACT: SOIL PROPERTIES AND CARBON ACCUMULATION IN AN INTEGRATED CROP-LIVESTOCK SYSTEM UNDER NO-TILLAGE
}

\begin{abstract}
In production systems such as the integrated crop-livestock system (ICL) under no-tillage, improvements have been observed in chemical, physical, and biological soil properties. Therefore, we aimed to evaluate the changes in chemical and physical soil properties, as well as carbon (C) accumulation, in an Oxisol under irrigated conditions in the Cerrado (Brazilian tropical savanna) in an ICL system under no-tillage. The experiment was carried during the growing of 2010/2011, 2011/2012, and 2012/2013. A randomized block experimental design with four replications was used. Treatments were arranged in split plots in time, and the experimental plots were composed of the following: maize and forage sorghum grown separately or intercropped with the forages Urochloa brizantha var. Xaraés and Megathyrsus maximum var. Tanzânia for ensiling; forage species in the between-harvest period; and the soybean crop in succession. In addition to the initial characterization, five evaluations (seasons) of the soil chemical and physical properties at the end of each production cycle were performed while carrying out the experiment. Production in the ICL system under no-tillage, even with high nutrient export and machine traffic, were efficient in maintaining and even improving soil fertility and soil C stocks. Over a three-year period, the ICL led to reduction in soil compaction through the positive effect of increased macroporosity and total porosity and decreased resistance to penetration and bulk density, in the 0-0.10 and 0.10-0.20 m soil layers.
\end{abstract}

Keywords: organic matter, cation exchange capacity, resistance to penetration, bulk density, soil carbon stock.

\section{INTRODUÇÃO}

O uso intensivo de solos da região de Cerrado para a produção agropecuária, aliado ao manejo inadequado do solo, tem causado a sua degradação com consequente diminuição da produtividade das culturas. Assim, há a necessidade da utilização de sistemas com bases conservacionistas, como é o caso do sistema plantio direto (SPD), da rotação de culturas e, mais recentemente, da integração lavoura-pecuária (ILP). O sucesso desses sistemas produtivos nessas regiões deve-se ao fato de que a palhada, acumulada pelas plantas de cobertura ou das pastagens e dos restos culturais de lavouras comerciais, proporciona um ambiente favorável à recuperação ou manutenção dos atributos físicos e químicos do solo (Flores et al., 2007; Santos et al., 2008; Chioderoli et al., 2012; Mendonça et al., 2013).

Em sistemas de produção como a ILP, têm sido observadas melhorias nos atributos químicos, físicos e biológicos do solo (Spera et al., 2010a; Santos et al., 2011; Mendonça et al., 2013), tendo em vista principalmente o efeito das adubações nas culturas, assim como a intensificação da utilização da área agrícola com cultivos realizados durante todo o ano, em que a rotação de culturas permite a inclusão de espécies com diferentes sistemas radiculares, além de resíduos vegetais com diferentes relações $\mathrm{C} / \mathrm{N}$, o que contribui para alterações das taxas de decomposição e ciclagem de nutrientes.

$\mathrm{O}$ uso e manejo inadequado do solo, além de contribuírem para a emissão de gases do efeito estufa, prejudicando o ambiente, ainda trazem inúmeros problemas relacionados à sua sustentabilidade em razão da degradação da matéria orgânica do solo (MOS), alterando negativamente os seus atributos físicos e químicos, bem como sua biodiversidade. Entretanto, práticas adequadas de manejo, que visam a manutenção ou mesmo o acúmulo de $\mathrm{C}$ no sistema solo-planta, podem atenuar os efeitos do aquecimento global (Carvalho et al., 2010). Os resíduos de matéria seca das plantas, além de promover um incremento no estoque de carbono (EC) do solo, permitem ainda recuperar os teores de MOS a valores próximos ao original (Wendling et al., 2005). Além disso, os resíduos vegetais são indispensáveis para os sistemas produtivos, tendo em vista que proporcionam inúmeros benefícios ao sistema solo-planta, sendo essenciais na agricultura de baixo carbono. 
A prática da ensilagem, utilizando-se das culturas produtoras de grãos consorciadas com espécies forrageiras tropicais na ILP, é relativamente recente. Entretanto, as pastagens formadas nesses sistemas produtivos têm funções que vão além da alimentação dos animais, pois devem contribuir também com a melhoria do ambiente de produção, fornecendo palhada para o SPD. Os resíduos vegetais presentes na superfície do solo beneficiam as culturas semeadas em sucessão, proporcionando melhorias nas propriedades físicas (agregação das partículas e diminuição da compactação do solo), químicas (aumento nos teores de MOS na decomposição e mineralização dos resíduos vegetais) e biológicas (aumento da atividade de microrganismos) do solo. $\mathrm{O}$ acúmulo de $\mathrm{C}$ em solos sob SPD também é fator de extrema relevância, em razão da necessidade de buscar técnicas que visem a qualidade ambiental nos cultivos atuais.

Tendo em vista as altas exportações de nutrientes e o uso intensivo da área agrícola nos sistemas de ILP com produção de silagem, torna-se importante avaliar a eficiência desses sistemas produtivos com vistas a preservar os atributos do solo que são primordiais na produção das culturas. Sendo assim, o objetivo deste trabalho foi de avaliar as alterações dos atributos químicos e físicos do solo e o acúmulo de carbono num Latossolo Vermelho distrófico típico argiloso, utilizado em sistema de integração lavoura-pecuária (ILP) em plantio direto (SPD) com irrigação, no Cerrado.

\section{MATERIAL E MÉTODOS}

O experimento foi conduzido durante os anos agrícolas de 2010/2011, 2011/2012 e 2012/2013 no município de Selvíria, Mato Grosso do Sul $\left(20^{\circ} 18^{\prime} \mathrm{S}\right.$ e $51^{\circ} 22^{\prime} \mathrm{W}$, altitude de $\left.370 \mathrm{~m}\right)$, em área irrigada (pivô central) na Fazenda de Ensino, Pesquisa e Extensão (FEPE) - Setor de Produção Vegetal da Faculdade de Engenharia de Ilha Solteira. A área experimental totaliza $2.304 \mathrm{~m}^{2}(80 \times 28,8 \mathrm{~m})$. Durante a condução do experimento, foram coletados mensalmente na estação meteorológica situada na FEPE os dados diários referentes às temperaturas máxima, média e mínima, fotoperíodo e precipitação pluvial (Figura 1). Os dados climáticos foram de acordo com a média histórica da região, com precipitação pluvial média anual de $1.370 \mathrm{~mm}$, temperatura média de $23,5{ }^{\circ} \mathrm{C}$ e umidade relativa do ar (UR) entre 70 e $80 \%$.

O solo da área foi classificado como Latossolo Vermelho distrófico típico argiloso (Santos et al., 2006) e foi cultivado com culturas anuais e semiperenes (milho, soja, sorgo forrageiro, guandu anão, Urochloa brizantha cv. Marandu, feijão, arroz e milho) em SPD há oito anos. A caracterização inicial dos atributos do solo foi efetuada em setembro de 2010. Para a determinação dos atributos químicos do solo, utilizaram-se os métodos propostos por Raij et al. (2001), em que foram coletadas 20 amostras de solo com estrutura deformada, realizadas com o auxílio de um trado de rosca na camada de 0-0,20 m. Essa amostra composta apresentou: $25 \mathrm{~g} \mathrm{dm}^{-3} \mathrm{de}$ matéria orgânica; $\mathrm{pH}\left(\mathrm{CaCl}_{2}\right) 5,1 ; 33 \mathrm{mg} \mathrm{dm}^{-3}$ de $\mathrm{P} ; 10 \mathrm{mg} \mathrm{dm}^{-3}$ de S-SO $\mathrm{SO}_{4}^{2-} ; 4,1 \mathrm{mmol}_{\mathrm{c}} \mathrm{dm}^{-3}$ de $\mathrm{K}^{+}$; $28 \mathrm{mmol}_{\mathrm{c}} \mathrm{dm}^{-3}$ de $\mathrm{Ca}^{2+} ; 16 \mathrm{mmol}_{\mathrm{c}} \mathrm{dm}^{-3} \mathrm{de}_{\mathrm{Mg}^{2+}}$; $0,0 \mathrm{mmol}_{\mathrm{c}} \mathrm{dm}^{-3} \mathrm{de} \mathrm{Al}^{3+} ; 29 \mathrm{mmol}_{\mathrm{c}} \mathrm{dm}^{-3} \mathrm{de} \mathrm{H}+\mathrm{Al} ;$ $48,1 \mathrm{mmol}_{\mathrm{c}} \mathrm{dm}^{-3}$ de soma de bases; $77,1 \mathrm{mmol}_{\mathrm{c}} \mathrm{dm}^{-3}$ de CTC e $62 \%$ de saturação por bases.

A análise granulométrica do solo da área experimental na camada de $0-0,20 \mathrm{~m}$ resultou nos valores de 482, 140 e $378 \mathrm{~g} \mathrm{~kg}^{-1}$ para as frações argila, silte e areia, respectivamente. Foram coletadas 20 amostras nas camadas de $0-0,10$ e 0,10-0,20 m, em pontos aleatórios na área experimental para

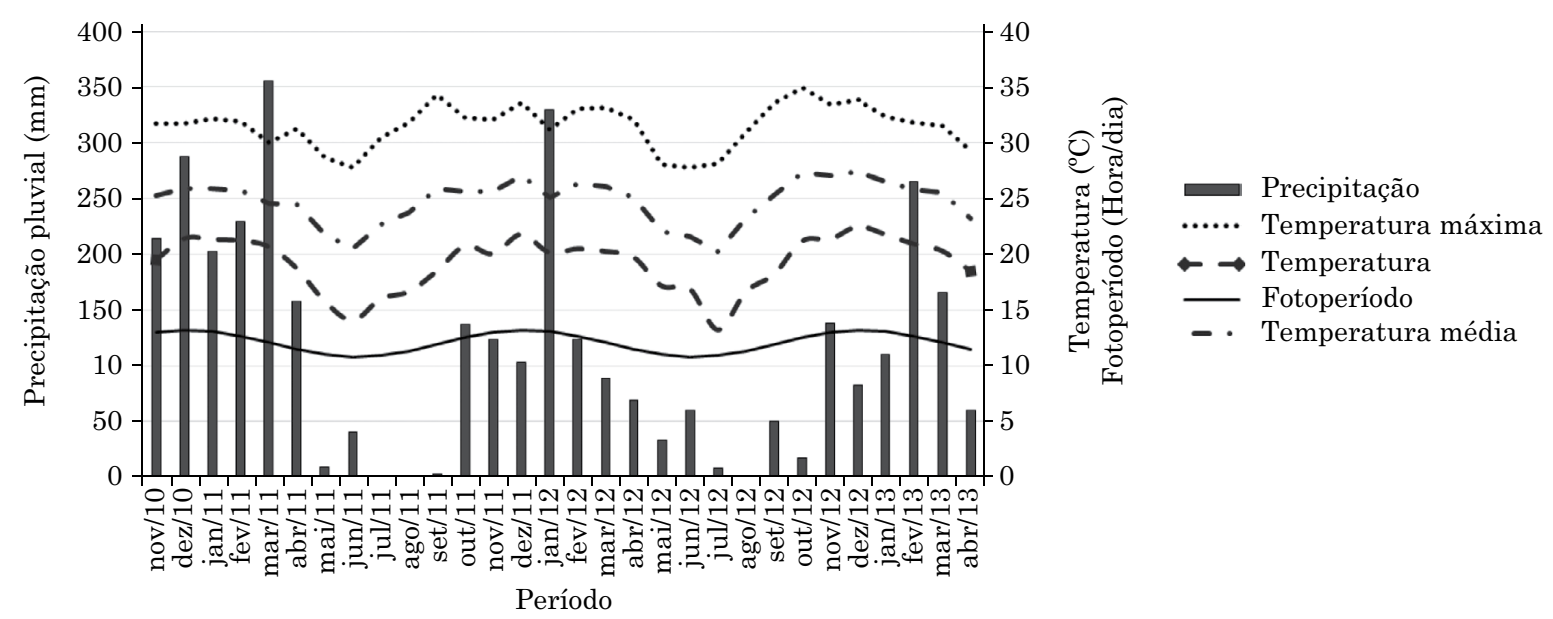

Figura 1. Dados climáticos obtidos na estação meteorológica situada na Fazenda de Ensino, Pesquisa e Extensão da FE/UNESP, no município de Selvíria, Mato Grosso do Sul. Período de novembro/2010 a abril/2013. 
caracterização inicial dos atributos físicos do solo: densidade (Ds), macroporosidade (MA), microporosidade (MI) e porosidade total (PT), pelo método do anel volumétrico e da mesa de tensão (Embrapa, 1997) (Quadro 1). Nesses mesmos pontos, determinaram-se os valores da resistência mecânica à penetração (RMP), utilizando o penetrômetro de impacto (Stolf, 1991). A leitura da resistência foi efetuada com associação à coleta de amostra para avaliar a umidade gravimétrica do solo nas camadas de $0-0,10 ; 0,10-0,20$; e 0,20-0,40 m, logo após a aplicação de lâmina de água via pivô central, para atingir $70 \%$ da capacidade de campo.

Os estoques de carbono (EC: $\mathrm{t} \mathrm{ha}^{-1}$ ) foram calculados a partir dos teores de $\mathrm{C}$ e dos valores da densidade do solo (Ds) na camada superficial de 0,20 m (Bernoux et al., 1998). Foram coletadas ainda amostras de solo em região de cerrado nativo, adjacente ao experimento, que foi tomado como referência, gerando um fator de correção para o estoque de C orgânico no solo. Para verificar tendências de acúmulo de $\mathrm{C}$ orgânico em comparação com o sistema de referência, foi calculada a variação do estoque de $\mathrm{C}$ em relação ao cerrado nativo $\left(\triangle \mathrm{EC}, \mathrm{Mg} \mathrm{ha}{ }^{-1} \mathrm{~cm}^{-1}\right)$, pela diferença entre os valores médios de EC neste sistema e em cada um dos demais, dividida pela espessura $(\mathrm{cm})$ de cada camada, o que foi considerado relevante para auxiliar a interpretação dos valores de EC (d'Andréa et al., 2004, Costa et al., 2008).

O delineamento experimental utilizado foi de blocos casualizados, com quatro repetições. Os tratamentos foram dispostos em parcelas subdivididas no tempo. As parcelas experimentais foram compostas pelos tratamentos com as culturas do milho e do sorgo forrageiro cultivadas exclusivamente (solteiras) ou consorciadas com as espécies forrageiras Urochloa brizantha cv. Xaraés (capim-xaraés) e Megathyrsus maximum cv. Tanzânia (capim-tanzânia) para ensilagem; pelas espécies forrageiras no período de entressafra, em que essas foram implantadas por ocasião do consórcio com as culturas produtoras de grãos ou após a colheita dessas; e pela cultura da soja em sucessão. Durante a condução dos experimentos, foi realizada a prática de adubação conforme as necessidades das culturas, tendo-se como base a análise química do solo (Raij et al., 1996).
Foram realizadas, durante a condução dos experimentos, cinco avaliações (épocas) dos atributos químicos e físicos do solo sempre ao final de cada ciclo produtivo. Para a avaliação dos atributos químicos, foram coletados cinco perfis de tradagem em cada subparcela na camada de $0-0,20 \mathrm{~m}$, visando formar uma amostra composta por subparcela, num total de 32 amostras por época de amostragem. Para os atributos físicos, coletaram-se três amostras por unidade experimental nas camadas de 0-0,10 e 0,10-0,20 m, utilizando-se o anel volumétrico com volume de $70,85 \mathrm{~cm}^{3}$ (altura de $4,00 \mathrm{~cm}$ e diâmetro de $4,75 \mathrm{~cm}$ ). Determinaram-se nesses mesmos pontos três perfis de resistência mecânica à penetração (RMP) por unidade experimental com o auxílio do penetrômetro de impacto (Stolf, 1991), efetuando-se a coleta de solo para avaliação da respectiva umidade gravimétrica $(0-0,10 ; 0,10-0,20 ;$ e $0,20-0,40$ $\mathrm{m}$ de profundidade). Os teores de carbono orgânico (C) no solo também foram determinados ao final de cada ciclo produtivo durante o experimento na ILP, assim como o realizado para as análises dos atributos químicos e físicos do solo.

As coletas de solo foram realizadas e divididas em: Época 1 (E1) - 14/04/2011, após a colheita dos experimentos com silagem de milho e sorgo; Época 2 (E2) - 29/10/2011, após o manejo das espécies forrageiras na entressafra, no primeiro ano agrícola; Época 3 (E3) - 29/03/2012, após a colheita dos experimentos com silagem de milho e sorgo; Época 4 (E4) - 22/10/2012, após o manejo das espécies forrageiras; e Época 5 (E5) - 03/04/2013, após a colheita da cultura da soja em sucessão, ambas no segundo ano agrícola.

Nesta pesquisa, tentou-se retratar um sistema de ILP; entretanto, por se tratar de condições experimentais, algumas premissas básicas do sistema não foram adotadas, principalmente pela ausência de condições satisfatórias para praticá-las. Dentre essas, destacou-se a ausência de animais durante o manejo das espécies forrageiras após a colheita das silagens, uma vez que existiu a possibilidade de compactação do solo pelo pisoteio animal. Entretanto, tentou-se simular o pastejo, realizando os cortes dos capins (três cortes durante o período de outono/primavera) com o auxílio de um triturador horizontal de resíduos vegetais (Triton); posteriormente, retirou-se o material vegetal da área.

Quadro 1. Caracterização inicial dos atributos físicos e do estoque de carbono do solo

\begin{tabular}{ccccccccc}
\hline Prof. & MA & MI & PT & Ds & RMP & UG & EC \\
\hline $\mathrm{m}$ & & $\mathrm{m}^{3} \mathrm{~m}^{-3}$ & & & $\mathrm{~kg} \mathrm{dm} \mathbf{n}^{-3}$ & $\mathrm{MPa}$ & $\mathrm{kg} \mathrm{kg}^{-1}$ & $\mathrm{tha}$ \\
$0-0,10$ & 0,071 & 0,354 & 0,435 & & 1,55 & 3,850 & 0,200 & 37,4 \\
$0,10-0,20$ & 0,093 & 0,361 & 0,454 & 1,50 & 2,953 & 0,217 & 37,4 \\
$0,20-0,40$ & - & - & - & - & 2,541 & 0,228 & - \\
\hline
\end{tabular}

MA: macroporosidade, MI: microporosidade, PT: porosidade total, Ds: densidade do solo, RMP: resistência mecânica à penetração, UG: umidade gravimétrica do solo e EC: estoque de carbono no solo. 
Os blocos foram considerados como efeitos aleatórios. Os sistemas produtivos avaliados durante o período e as épocas de coleta dos atributos químicos e físicos do solo foram considerados como efeitos fixos. Os resultados foram submetidos à análise de variância e para variáveis com efeito significativo pelo teste $\mathrm{F}(\mathrm{p}<0,05)$, as médias foram comparadas pelo teste $t$ de Student $(p<0,05)$. As análises estatísticas foram realizadas utilizando o software Sisvar $^{\circledR}$ (Ferreira, 1999).

\section{RESULTADOS E DISCUSSÃO}

Durante a condução dos experimentos na ILP em SPD, pôde-se constatar a exportação de nutrientes proporcionada pela colheita da parte aérea das culturas (silagem e pastagem) e de grãos (soja) durante o período de avaliação (Quadro 2). A produtividade de matéria seca de silagem, de forragem (entressafra) e de grãos de soja em sucessão demonstrou a viabilidade desses sistemas produtivos na região em estudo, em condições semelhantes às praticadas neste trabalho, uma vez que esses valores estão acima dos verificados por Neumann et al. (2008) e Paziani et al. (2009), para silagem de milho e sorgo; Benett et al. (2008) e Pariz et al. (2011), para forragem e CONAB (2013) para soja.

De acordo com os resultados, o sistema de ILP, por meio do cultivo consorciado, pode suprir a necessidade do agricultor tanto na produção de silagem de milho e sorgo quanto para formação de pastagem na entressafra e produção de grãos de soja. Entretanto, durante o período de condução do experimento, realizou-se adubação mineral em todos os cultivos, inclusive durante o manejo de corte dos capins, utilizando-se ureia como fonte de $\mathrm{N}$ (70 kg ha-1 por corte). Houve, ainda, além da colheita das culturas, o aporte de matéria

Quadro 2. Produtividade média de matéria seca das silagens (PMSs) e de matéria seca das espécies forrageiras (PMSf) acumulado em três cortes durante o período de entressafra: outono/primavera e produtividade de grãos de soja (PG) cultivados em sucessão na integração lavoura-pecuária, durante os anos agrícolas de 2010/2011, 2011/2012 e 2012/2013

\begin{tabular}{lccc}
\hline Época de avaliação & PMSs & PMSf & PG \\
\hline & \multicolumn{3}{c}{$\mathrm{kg} \mathrm{ha}^{-1}$} \\
(E1) $14 / 04 / 2011$ & 26.340 & - & - \\
(E2) $29 / 10 / 2011$ & - & 9.147 & - \\
(E3) $29 / 03 / 2012$ & 34.166 & - & - \\
(E4) $22 / 10 / 2012$ & - & 6.470 & - \\
(E5) $03 / 04 / 2013$ & - & - & 2.911 \\
\hline
\end{tabular}

seca das espécies forrageiras após o manejo de corte (outono/primavera), visando à formação de palhada para continuidade e manutenção do SPD na área, com produtividade média de matéria seca (PMS) próxima a 6.320 e $6.159 \mathrm{~kg} \mathrm{ha}^{-1}$ para os anos agrícolas de 2011/2012 (E2) e 2012/2013 (E4), respectivamente (dados não apresentados).

A quantidade de matéria seca de palhada acumulada protege o solo contra a erosão; pelos processos de decomposição e mineralização dos resíduos vegetais pode liberar quantidades consideráveis de nutrientes ao sistema produtivo, principalmente de $\mathrm{N}$ e $\mathrm{K}$, beneficiando as culturas cultivadas em sucessão na área. A PMS das forrageiras foi considerada satisfatória, uma vez que os valores estão próximos aos $6.000 \mathrm{~kg} \mathrm{ha}^{-1}$ de matéria seca anual, valores esses relatados como quantidade ideal para adição ao sistema como afirmou Ruedell (1998); portanto, tornando-se excelente opção como culturas produtoras de palhada na região em estudo (Cerrado de baixa altitude).

Sendo assim, a relevância do SPD no cenário agrícola brasileiro, em que esse sistema é o grande responsável pelo significativo aumento da produtividade e a continuidade da exploração agrícola no país, deve-se pelas características dos solos cultivados, principalmente os da região de cerrado, uma vez que esses possuem baixa fertilidade natural, e a palhada fornecida pelas espécies forrageiras, ou na rotação de culturas, pode proporcionar, em longo prazo, melhorias significativas nos atributos químicos, físicos e biológicos do solo. Atualmente, os sistemas de ILP podem auxiliar no fornecimento de nutrientes pelo efeito residual da adubação na cultura produtora de grãos. Esses fatores, aliados à irrigação e ao correto manejo da pastagem e do solo, proporcionam forragem de excelente qualidade além de palhada para o SPD.

Verificou-se que houve diferença entre as áreas de cultivo com relação aos atributos químicos do solo; os maiores valores, principalmente de $\mathrm{P}, \mathrm{MO}, \mathrm{pH}, \mathrm{K}, \mathrm{Ca}, \mathrm{Mg}, \mathrm{SB}, \mathrm{S}, \mathrm{CTC}$ e V ocorreram na área em que havia sido cultivado o milho, independentemente da espécie forrageira utilizada no sistema produtivo (Quadro 3). Entre as modalidades de semeadura das espécies forrageiras (se implantadas em razão do consórcio ou da sucessão às culturas produtoras de grãos), constatou-se que os maiores valores dos atributos químicos do solo foram obtidos quando os capins foram implantados em sucessão ao milho e sorgo, apresentando os maiores valores para $\mathrm{MO}, \mathrm{Ca}, \mathrm{Mg}$, SB, CTC e V (Quadro 3). Constatou-se que houve melhoria na qualidade química do solo conforme se deram os cultivos sucessivos durante as épocas de avaliação; nas últimas coletas, foram verificados os maiores teores de nutrientes do solo. 
Quadro 3. Média dos atributos químicos do solo na camada de 0-0,20 m em sistemas de integração lavoura-pecuária de acordo com o sistema de manejo (consórcio ou sucessão) das culturas do milho e do sorgo com as espécies forrageiras capim-xaraés e capim-tanzânia e soja em sucessão, épocas de avaliação $\left(E_{i}\right)$ e valor-p do $F$ para as interações entre os tratamentos, o sistema de manejo e a época de avaliação

\begin{tabular}{|c|c|c|c|c|c|c|c|c|c|c|c|c|c|}
\hline Variável & $\mathbf{P}$ & MO & $\mathrm{pH}\left(\mathrm{CaCl}_{2}\right)$ & $\mathbf{K}^{+}$ & $\mathrm{Ca}^{2+}$ & $\mathrm{Mg}^{2+}$ & $\mathrm{H}+\mathrm{Al}$ & $\mathrm{Al}^{3+}$ & SB & CTC & ${\mathrm{S}-\mathrm{SO}_{4}^{-}}^{-}$ & $\mathrm{V}$ & $\mathbf{m}$ \\
\hline & $\mathrm{mg} \mathrm{dm^{-3 }}$ & $\mathrm{g} \mathrm{dm}^{-3}$ & & \multicolumn{7}{|c|}{$\mathrm{mmol}_{\mathrm{c}} \mathrm{dm}^{-3}$} & $\mathrm{mg} \mathrm{dm} \mathrm{m}^{-3}$ & \multicolumn{2}{|r|}{$\%$} \\
\hline \multicolumn{14}{|l|}{ Tratamento $(\mathrm{T})^{(1)}$} \\
\hline Milho/capim-xaraés/soja & $27,1 \mathrm{a}$ & 22,5 & $4,8 \mathrm{~b}$ & $3,3 \mathrm{~b}$ & $19,6 \mathrm{a}$ & $10,8 \mathrm{~b}$ & $38,9 \mathrm{~b}$ & $3,6 \mathrm{~b}$ & $33,7 \mathrm{~b}$ & $72,6 \mathrm{a}$ & $5,5 \mathrm{a}$ & $45,0 \mathrm{~b}$ & $12,5 \mathrm{a}$ \\
\hline Sorgo/capim-xaraés/soja & $16,5 \mathrm{c}$ & 22,1 & $4,6 \mathrm{~d}$ & $2,3 \mathrm{c}$ & $14,7 \mathrm{~b}$ & $9,3 \mathrm{c}$ & $41,4 \mathrm{a}$ & $4,9 \mathrm{a}$ & $26,3 \mathrm{~d}$ & $67,7 \mathrm{c}$ & $5,0 \mathrm{a}$ & $38,1 \mathrm{c}$ & $8,0 \mathrm{~b}$ \\
\hline Milho/capim-tanzânia/soja & $24,2 \mathrm{ab}$ & 22,5 & $4,9 \mathrm{a}$ & $3,6 \mathrm{a}$ & $21,1 \mathrm{a}$ & $12,2 \mathrm{a}$ & $36,0 \mathrm{c}$ & $2,3 \mathrm{c}$ & $36,9 \mathrm{a}$ & $72,9 \mathrm{a}$ & $4,1 \mathrm{~b}$ & 49,6 & $7,7 \mathrm{c}$ \\
\hline Sorgo/capim-tanzânia/soja & $17,7 \mathrm{~b}$ & 22,5 & $4,7 \mathrm{c}$ & $2,4 \mathrm{c}$ & $16,4 \mathrm{~b}$ & $10,7 \mathrm{~b}$ & $40,3 \mathrm{a}$ & $3,9 \mathrm{~b}$ & $29,5 \mathrm{c}$ & $69,9 \mathrm{~b}$ & $4,3 \mathrm{~b}$ & $42,1 \mathrm{~b}$ & $12,8 \mathrm{a}$ \\
\hline \multicolumn{14}{|l|}{ Sistema de manejo (S) } \\
\hline Consórcio & 21,4 & $21,8 \mathrm{~b}$ & $4,6 \mathrm{~b}$ & 2,9 & $13,1 \mathrm{~b}$ & $8,6 \mathrm{~b}$ & $42,0 \mathrm{a}$ & $5,1 \mathrm{a}$ & $25,7 \mathrm{~b}$ & $66,6 \mathrm{~b}$ & $3,8 \mathrm{~b}$ & $36,8 \mathrm{~b}$ & $18,6 \mathrm{a}$ \\
\hline Sucessão & 21,4 & $23,1 \mathrm{a}$ & $4,9 \mathrm{a}$ & 2,9 & $22,8 \mathrm{a}$ & $12,9 \mathrm{a}$ & $36,3 \mathrm{~b}$ & $2,2 \mathrm{~b}$ & $38,6 \mathrm{a}$ & $74,9 \mathrm{a}$ & $5,6 \mathrm{a}$ & $50,6 \mathrm{a}$ & $6,9 \mathrm{~b}$ \\
\hline \multicolumn{14}{|l|}{ Época $(E)^{(2)}$} \\
\hline E1 & 24,1 & $20,6 \mathrm{c}$ & $4,9 \mathrm{a}$ & $2,8 \mathrm{~b}$ & $17,5 \mathrm{~b}$ & $10,3 \mathrm{~b}$ & $36,2 \mathrm{c}$ & $3,5 \mathrm{~b}$ & $30,5 \mathrm{~b}$ & $66,7 \mathrm{c}$ & $7,5 \mathrm{a}$ & $44,4 \mathrm{a}$ & $13,1 \mathrm{a}$ \\
\hline E2 & 19,5 & $22,5 \mathrm{~b}$ & $4,8 \mathrm{~b}$ & $3,4 \mathrm{a}$ & $17,3 \mathrm{~b}$ & $10,5 \mathrm{~b}$ & $39,7 \mathrm{~b}$ & $4,5 \mathrm{a}$ & $31,2 \mathrm{~b}$ & $70,9 \mathrm{a}$ & $3,2 \mathrm{c}$ & $43,2 \mathrm{~b}$ & $14,5 \mathrm{a}$ \\
\hline E3 & 24,2 & $23,7 \mathrm{a}$ & $4,7 \mathrm{c}$ & $2,5 \mathrm{c}$ & $16,6 \mathrm{~b}$ & $10,2 \mathrm{~b}$ & $39,5 \mathrm{~b}$ & $4,2 \mathrm{a}$ & $29,3 \mathrm{~b}$ & $68,8 \mathrm{bc}$ & $4,0 \mathrm{~b}$ & $41,4 \mathrm{~b}$ & $15,3 \mathrm{a}$ \\
\hline $\mathrm{E} 4$ & 18,3 & $22,9 \mathrm{ab}$ & $4,7 \mathrm{c}$ & $2,6 \mathrm{c}$ & $18,0 \mathrm{~b}$ & $10,8 \mathrm{~b}$ & $42,0 \mathrm{a}$ & $3,4 \mathrm{~b}$ & $31,4 \mathrm{~b}$ & $73,4 \mathrm{a}$ & $4,9 \mathrm{~b}$ & $42,2 \mathrm{~b}$ & $12,2 \mathrm{ab}$ \\
\hline \multicolumn{13}{|c|}{ Valor p para F } & $8,7 \mathrm{~b}$ \\
\hline $\mathrm{T} \times \mathrm{S}$ & 0,553 & 0,054 & 0,159 & 0,210 & 0,174 & 0,132 & 0,063 & 0,078 & 0,178 & 0,222 & 0,765 & 0,171 & 0,974 \\
\hline $\mathrm{T} \times \mathrm{E}$ & 0,828 & 0,525 & 0,882 & 0,290 & 0,804 & 0,909 & 0,949 & 0,994 & 0,805 & 0,101 & 0,677 & 0,933 & 0,999 \\
\hline $\mathrm{S} \times \mathrm{E}$ & 0,360 & 0,182 & 0,354 & 0,208 & 0,835 & 0,501 & 0,549 & 0,863 & 0,649 & 0,226 & 0,726 & 0,451 & 0,650 \\
\hline $\mathrm{T} \times \mathrm{S} \times \mathrm{E}$ & 0,253 & 0,881 & 0,677 & 0,360 & 0,507 & 0,813 & 0,857 & 0,856 & 0,467 & 0,161 & 0,343 & 0,635 & 0,840 \\
\hline CV (\%) & 29,27 & 9,14 & 3,66 & 24,27 & 25,68 & 21,44 & 12,04 & 23,81 & 21,74 & 21,32 & 9,10 & 15,57 & 29,01 \\
\hline
\end{tabular}

CV: coeficiente de variação. Médias seguidas de letras distintas nas colunas diferem entre si, pelo teste t de Student a $5 \%$. (1) Tratamentos: milho e sorgo solteiro ou consorciado com as forrageiras capim-xaraés ou capim-tanzânia para ensilagem; forrageiras no período de entressafra, em que estas foram implantadas por ocasião do consórcio com as culturas produtoras de grãos ou após a colheita dessas; e soja em sucessão. ${ }^{(2)}$ E1: 14/04/2011 e E3: 29/03/2012, após a colheita silagem de milho e sorgo no primeiro e segundo ano, respectivamente; E2: 29/10/2011 e E4: 22/10/2012, após o manejo das espécies forrageiras na entressafra no primeiro e segundo ano e E5: 03/04/2013, após a colheita da cultura da soja em sucessão.

As alterações dos atributos químicos do solo resultaram do elevado acúmulo de resíduos vegetais sobre sua superfície durante a condução do experimento, onde esses, no processo de decomposição da massa vegetal residual, proporcionaram aporte de nutrientes ao solo, causando estímulo à atividade biológica que resultaram em alterações na sua fertilidade. Entretanto, os valores dos atributos químicos do solo, de maneira geral, foram inferiores aos avaliados anteriormente à instalação do experimento.

Com os cultivos consecutivos na área, verificou-se que houve a manutenção de sua fertilidade, com destaque após o cultivo das forrageiras na entressafra (E2 e E4, respectivamente) e após o cultivo da cultura da soja, ao final do ciclo de sucessão de gramíneas na área (E5), mesmo com a alta exportação de silagem (milho e sorgo), forragem (entressafra) e grãos (soja), conforme pode ser verificado no quadro 2 . Não obstante, deve-se salientar que todos os ciclos produtivos de silagem e soja foram adubados conforme a necessidade da cultura, com base em meta de produtividade e teores de nutrientes do solo (Raij et al., 1996), e as forrageiras foram adubadas com $\mathrm{N}$ a cada ciclo de corte. Dessa forma, não houve degradação da fertilidade do solo; em contrapartida, pelos resíduos vegetais e pelo aporte de material orgânico resultaram em melhoria de seus atributos físicos.

Apesar de os cultivos subsequentes e da elevada exigência e extração de nutrientes pela maioria das culturas avaliadas, principalmente no caso da produção de silagem e quando essas são consorciadas, os sistemas produtivos analisados foram eficientes em manter os níveis de fertilidade do solo durante o período, inclusive com aumento e, ou, melhoria dos teores de nutrientes com os cultivos no curto prazo, tendo em vista que as culturas foram adubadas conforme a necessidade, uma vez que a fertilidade do solo desempenha papel de extrema importância no desenvolvimento das plantas e na sua produtividade. 
O manejo adotado durante a condução dos experimentos permitiu ainda que não houvesse somente a extração/exportação de nutrientes pelos cultivos consecutivos. As práticas de adubação mineral, a produção de palhada para manutenção e a continuidade do SPD, com acúmulo de resíduos vegetais, proporcionaram condições satisfatórias para que houvesse também a manutenção de nutrientes no sistema, podendo refletir em economia na utilização de fertilizantes quando comparado aos sistemas de produção menos conservacionistas, ou seja, preparo convencional do solo ou sucessão de culturas erroneamente denominada de rotação. Sendo assim, os sistemas produtivos utilizados nesta pesquisa foram determinantes na manutenção dos atributos químicos do solo em níveis satisfatórios para a região de Cerrado.

Normalmente, há redução na disponibilidade de bases do solo associada à extração de nutrientes pelas culturas, principalmente em sistemas de rotação com alta exportação (silagem) como os avaliados neste trabalho. Portanto, torna-se necessária a adoção de práticas conservacionistas de manejo do solo e das culturas, tendo em vista principalmente melhorá-lo química, física e biologicamente, criando condições favoráveis ao desenvolvimento agrícola. Assim, o SPD é uma excelente alternativa nesses sistemas produtivos, onde a presença de resíduos vegetais na superfície do solo pode proporcionar aumento do $\mathrm{pH}$, dos teores de $\mathrm{Ca}$ e $\mathrm{Mg}$ trocáveis de camadas mais profundas do solo, em detrimento do teor de $\mathrm{Al}$ trocável, além de aumento nos teores de $\mathrm{C}$ orgânico, $\mathrm{MO}$ e $\mathrm{P}$ das camadas mais superficiais do solo (Silveira e Stone, 2001; Lourente et al., 2010), resultados esses semelhantes aos verificados nesta pesquisa.

Apesar de os teores de $\mathrm{P}, \mathrm{K}, \mathrm{Ca}, \mathrm{Mg}$ e $\mathrm{S}$ terem diminuído a partir do primeiro cultivo (Quadro 3), em relação aos teores iniciais no solo, cabe ressaltar que, principalmente para os teores de $\mathrm{K}, \mathrm{Ca}$ e $\mathrm{Mg}$, houve aumento conforme foram adicionados resíduos vegetais provenientes dos capins cultivados no período de entressafra. Tal fato se deve, provavelmente, ao elevado acúmulo desses nutrientes, principalmente de $\mathrm{K}$ pelos capins utilizados como palhada para o SPD. Calonego et al. (2005), trabalhando com milheto, demonstraram que à medida que a planta dessecada senesce e recebe chuvas essa libera $\mathrm{K}$, que é retornado ao solo.

Em sistemas de produção intensivos, como os apresentados nesta pesquisa em ILP, onde não há período de pousio entre uma cultura e outra, ou seja, a área é cultivada durante praticamente todos os meses do ano, o K absorvido pelas culturas permanece a maior parte do tempo no tecido vegetal, protegido de perdas por erosão e lixiviação. As maiores perdas de $\mathrm{K}$ nesses sistemas produtivos devem-se principalmente pela colheita de grãos e da parte aérea das culturas, como no caso da silagem. Dessa maneira, o aumento no rendimento de matéria seca das culturas, pelo melhoramento da fertilidade e pelo bom uso do solo, intensifica a ciclagem de $\mathrm{K}$ (Ferreira et al., 2011).

$\mathrm{Na}$ produção de silagem, ao contrário do que ocorre com a colheita de grãos, em que a colhedora colhe uma ampla faixa da cultura em cada passada pela área (tamanho variável em razão da plataforma da colhedora), a colheita para silagem com colhedoras de forragem de uma linha de $0,90 \mathrm{~m}$, acopladas ao trator, aumenta o tráfego na área, inclusive com o rodado do trator passando sobre quase todas as linhas de semeadura. Além disso, o peso da carreta carregada de material para ensilagem também não pode ser desconsiderado. Esse tráfego excessivo de máquinas na área, uma vez que há o cultivo de culturas durante todos os meses do ano, inclusive considerando-se as operações de semeadura, adubação e aplicações de inseticidas ao longo do tempo, pode proporcionar alterações nos atributos físicos do solo, causando sua compactação e prejudicando o desenvolvimento das culturas em sucessão. De modo geral, mesmo com esses possíveis efeitos de compactação do solo, pelo histórico de SPD, com práticas de rotação adequadas, os sistemas testados não determinaram a degradação física do solo, inclusive com melhoria dos atributos, após as cinco épocas de avaliação (Quadro 4). Cabe destacar que, pela altura de colheita da silagem e forragem nos ciclos de corte $(0,30 \mathrm{~m})$, houve aporte suficiente de palhada, deixando o solo coberto no momento do tráfego de maquinário nas operações agrícolas de implantação, tratos culturais e colheita.

Nesta pesquisa, não se considerou o pisoteio animal, uma vez que não houve a sua presença no experimento, sendo somente simulado o pastejo (corte dos capins e posterior retirada do material vegetal da área). O intenso pisoteio animal no solo ocasiona pressão superior às máquinas agrícolas; entretanto, em camadas superficiais, geralmente nos primeiros 0,05 a 0,08 m (Flores et al., 2007; Lopes et al., 2009). Em contrapartida, as máquinas agrícolas, apesar de seu maior peso, exercem pressão menor sobre a superfície do solo, uma vez que têm melhor distribuição desse peso por área (pneus) (Hamza e Anderson, 2005). A pressão exercida sobre o solo é o agente causador da compactação; entretanto, a camada de palha na superfície do solo é grande atenuador desse efeito, fato esse que deve ser considerado em sistemas conservacionistas como os aqui testados, em que ao longo do tempo houve redução da Ds com incremento da MA e PT, tanto nas camadas superficiais $(0-0,10 \mathrm{~m})$ como nas subsuperficiais $(0,10-0,20 \mathrm{~m})$ (Quadro 4).

O manejo incorreto do solo pode provocar declínio de produção das culturas de modo geral, tendo em vista que esse é decorrente da degradação dos atributos físicos e da exportação dos nutrientes, bem como do esgotamento das reservas do solo. Assim, as práticas conservacionistas, como as adotadas 
Quadro 4. Macroporosidade (MA), microporosidade (MI), porosidade total (PT) e densidade do solo (Ds) nas camadas de 0-0,10 e 0,10-0,20 m durante a condução de sistemas de integração lavoura-pecuária de acordo com o sistema de manejo (consórcio ou sucessão) das culturas do milho e do sorgo com as espécies forrageiras capim-xaraés e capim-tanzânia e soja em sucessão, épocas de avaliação (Ei) e valor-p do F para as interações entre os tratamentos, o sistema de manejo e época de avaliação

\begin{tabular}{|c|c|c|c|c|c|c|c|c|}
\hline Variável & MA10 & MI10 & PT10 & MA20 & MI20 & PT20 & Ds10 & Ds20 \\
\hline & \multicolumn{6}{|c|}{$\mathrm{m}^{3} \mathrm{~m}^{-3}$} & \multicolumn{2}{|c|}{$\mathrm{kg} \mathrm{dm}^{-3}$} \\
\hline \multicolumn{9}{|l|}{ Tratamento $(\mathrm{T})^{(1)}$} \\
\hline Milho/capim-xaraés/soja & $0,066 \mathrm{~b}$ & $0,343 \mathrm{a}$ & $0,409 \mathrm{~b}$ & 0,084 & 0,336 & 0,417 & $1,57 \mathrm{a}$ & $1,52 \mathrm{~b}$ \\
\hline Sorgo/capim-xaraés/soja & $0,076 \mathrm{a}$ & $0,340 \mathrm{a}$ & 0,416 a & 0,081 & 0,333 & 0,414 & $1,54 \mathrm{~b}$ & $1,52 \mathrm{~b}$ \\
\hline Milho/capim-tanzânia/soja & $0,065 \mathrm{~b}$ & $0,337 \mathrm{~b}$ & $0,402 \mathrm{c}$ & 0,078 & 0,333 & 0,411 & $1,59 \mathrm{a}$ & $1,55 \mathrm{a}$ \\
\hline Sorgo/capim-tanzânia/soja & $0,070 \mathrm{a}$ & $0,343 \mathrm{a}$ & $0,414 \mathrm{a}$ & 0,084 & 0,330 & 0,414 & $1,56 \mathrm{a}$ & $1,53 \mathrm{a}$ \\
\hline \multicolumn{9}{|l|}{ Sistema de manejo (S) } \\
\hline Consórcio & 0,070 & 0,341 & 0,411 & 0,080 & $0,335 \mathrm{a}$ & 0,414 & 1,56 & 1,53 \\
\hline Sucessão & 0,068 & 0,341 & 0,409 & 0,083 & $0,331 b$ & 0,414 & 1,56 & 1,53 \\
\hline \multicolumn{9}{|l|}{ Época $(E)^{(2)}$} \\
\hline E1 & $0,052 \mathrm{c}$ & $0,350 \mathrm{a}$ & $0,402 \mathrm{c}$ & $0,062 \mathrm{~d}$ & $0,340 \mathrm{~b}$ & $0,402 \mathrm{c}$ & $1,60 \mathrm{a}$ & $1,56 \mathrm{a}$ \\
\hline E2 & $0,069 \mathrm{~b}$ & $0,345 \mathrm{a}$ & $0,414 \mathrm{a}$ & $0,085 \mathrm{~b}$ & $0,338 \mathrm{~b}$ & $0,423 \mathrm{a}$ & $1,55 \mathrm{~b}$ & $1,51 \mathrm{~b}$ \\
\hline E3 & $0,063 \mathrm{~b}$ & $0,349 \mathrm{a}$ & $0,412 \mathrm{a}$ & $0,077 \mathrm{c}$ & $0,344 \mathrm{a}$ & $0,418 \mathrm{a}$ & $1,57 \mathrm{~b}$ & $1,52 \mathrm{~b}$ \\
\hline $\mathrm{E} 4$ & $0,069 \mathrm{~b}$ & $0,337 \mathrm{~b}$ & $0,406 \mathrm{~b}$ & $0,087 \mathrm{~b}$ & $0,324 \mathrm{~b}$ & $0,412 \mathrm{~b}$ & $1,55 \mathrm{~b}$ & $1,53 \mathrm{~b}$ \\
\hline E5 & $0,094 \mathrm{a}$ & $0,323 \mathrm{c}$ & $0,417 \mathrm{a}$ & $0,096 \mathrm{a}$ & $0,319 \mathrm{~b}$ & $0,415 \mathrm{~b}$ & $1,54 \mathrm{~b}$ & $1,53 \mathrm{~b}$ \\
\hline \multicolumn{9}{|c|}{ Valor p para $\mathrm{F}$} \\
\hline $\mathrm{T} \times \mathrm{S}$ & 0,261 & 0,196 & 0,162 & 0,342 & 0,209 & 0,224 & 0,310 & 0,350 \\
\hline $\mathrm{T} \times \mathrm{E}$ & 0,530 & 0,159 & 0,845 & 0,852 & 0,321 & 0,756 & 0,573 & 0,698 \\
\hline $\mathrm{S} \times \mathrm{E}$ & 0,320 & 0,420 & 0,197 & 0,142 & 0,856 & 0,606 & 0,267 & 0,260 \\
\hline $\mathrm{T} \times \mathrm{S} \times \mathrm{E}$ & 0,665 & 0,828 & 0,621 & 0,489 & 0,699 & 0,967 & 0,788 & 0,797 \\
\hline CV (\%) & 27,23 & 2,78 & 4,12 & 20,87 & 3,76 & 3,51 & 4,12 & 2,88 \\
\hline
\end{tabular}

CV: coeficiente de variação. Médias seguidas de letras distintas nas colunas diferem entre si, pelo teste t de Student a $5 \%$.

(1) Tratamentos: milho e sorgo solteiro ou consorciado com as forrageiras capim-xaraés ou capim-tanzânia para ensilagem; forrageiras no período de entressafra, em que estas foram implantadas por ocasião do consórcio com as culturas produtoras de grãos ou após a colheita dessas; e soja em sucessão. ${ }^{(2)}$ E1: 14/04/2011 e E3: 29/03/2012, após a colheita silagem de milho e sorgo no primeiro e segundo ano, respectivamente; E2: 29/10/2011 e E4: 22/10/2012, após o manejo das espécies forrageiras na entressafra no primeiro e segundo ano e E5: 03/04/2013, após a colheita da cultura da soja em sucessão.

neste trabalho, e o correto uso da adubação podem beneficiar o sistema de produção, melhorando os atributos físicos e químicos do solo (Quadros 3 e 4).

Verificou-se que entre os atributos macro (MA10), micro (MI10) e porosidade total (PT10) na camada de 0-0,10 m houve influência significativa das áreas de cultivo e espécies forrageiras utilizadas no período de entressafra, sendo os maiores valores desses indicadores obtidos na área em que foi cultivada a cultura do sorgo para ensilagem, independentemente da espécie forrageira utilizada na entressafra (Quadro 4). Tal fato se deve, provavelmente, ao sistema radicular da cultura do sorgo forrageiro, que é mais profundo e pode ter promovido maior aeração do solo, aumentando as porosidades e reduzindo consequentemente a sua densidade durante os cultivos, quando comparado ao da cultura do milho.

Para esses mesmos atributos na camada de 0,10-0,20 m (MA20, MI20 e PT20), não foram verificados efeitos significativos; entretanto, para a Ds, nas duas camadas avaliadas, os maiores valores foram obtidos quando a espécie forrageira utilizada foi o capim-tanzânia, independentemente da cultura antecessora (milho ou sorgo). De maneira geral, as modalidades de semeadura das forrageiras não influenciaram os atributos físicos do solo, com exceção à MI20, em que as espécies implantadas por ocasião do consórcio proporcionaram o maior valor.

De maneira geral, os atributos MA, MI e PT em ambas as profundidades de coleta foram inferiores aos observados antes da instalação do experimento (Quadro 1), principalmente nas primeiras épocas de condução do experimento (Quadro 4). Cabe ressaltar as alterações na porosidade do solo durante o período avaliado, em que houve diferença significativa para MA e MI nas duas camadas, com incremento conforme os sucessivos cultivos. Com relação à Ds, verificou-se efeito oposto, em que durante os cultivos houve redução gradativa deste atributo. 
A Ds foi maior na camada mais superficial do solo; quanto maior a densidade, menor a PT. Tal fato se deve ao histórico da área de cultivo e ao tempo de adoção do SPD, aproximadamente oito-nove anos, onde o não revolvimento do solo pode causar adensamento das camadas superficiais em razão principalmente ao tráfego de máquinas, como já citado anteriormente, e que nesta pesquisa foi intenso, uma vez que se trata de um sistema de ILP, caracterizado pela intensidade de cultivos na área.

Houve redução dos valores da Ds a partir da segunda época de avaliação (E2) (Quadro 3). Sendo assim, esses resultados estão condicionados ao aumento da PT, em que a redução nos valores da Ds provavelmente ocorreu por causa de o solo ser explorado por sistemas radiculares distintos (gramíneas e leguminosas), uma vez que, após a decomposição da massa radicular, contribuem para formação de uma arquitetura de poros permanentes, conferindo ao solo maior MA e, consequentemente, menor densidade. Esse comportamento também foi observado por diversos autores na mesma região em estudo, os quais obtiveram melhoria nesses atributos do solo quando utilizaram a rotação de culturas, principalmente com o consórcio do milho com espécies forrageiras tropicais, de pastagem e da cultura da soja em sucessão (Chioderoli et al., 2012; Mendonça et al., 2013).

Tomando-se como objetivo o manejo adequado do solo para fins conservacionistas, Spera et al. (2009) afirmaram que o aumento de macroporos é o aspecto mais importante e o valor da MA menor que $0,10 \mathrm{~m}^{3} \mathrm{~m}^{-3}$ pode tornar-se crítico. Entretanto, conforme relatado por Lanzanova et al. (2007), em valores abaixo de $0,10 \mathrm{~m}^{3} \mathrm{~m}^{-3}$, como os obtidos neste trabalho, não interferiram na produção das culturas utilizadas nos sistemas produtivos, tendo em vista que essas atingiram elevados valores de produção. Assim, para solos tropicais em cultivos irrigados, esse limite de $0,10 \mathrm{~m}^{3} \mathrm{~m}^{-3}$ pode não ser o real valor limitante à produção agrícola.

Em trabalho realizado por Mendonça et al. (2013), avaliando as alterações dos atributos físicos do solo no sistema ILP em SPD, em condições edafoclimáticas semelhantes às condições deste estudo, verificaram valores para MA, MI, PT e Ds próximos dos constatados nesta pesquisa. De acordo com esses mesmos autores, a sucessão milho e soja resultou em melhoria nos atributos físicos do solo, independentemente do uso de forrageiras consorciadas com o milho, sendo esse o sistema de rotação de culturas indicado em região de Cerrado no SPD para melhoria dos atributos físicos do solo.

Os benefícios dos sistemas integrados de produção também foram comprovados por Chioderoli et al. (2012), na mesma região deste estudo, indicando que o sistema de ILP pode melhorar as condições físicas e químicas do solo, em razão da maior produção de palha proporcionada pelo consórcio, o que melhora a cobertura do solo, promove aporte de matéria orgânica, favorece a infiltração de água, permite maior exploração do perfil do solo pelas raízes, diminui o processo erosivo e, consequentemente, mantém a estabilidade do sistema.

A inclusão de pastagens na rotação de culturas provoca melhoria da qualidade física do solo por causa da combinação de três efeitos principais: ausência de preparo durante o ciclo da pastagem, presença de um denso sistema radicular atuando como agente agregante e aumento da atividade da macrofauna do solo (Marchão et al., 2007). Corroborando a essa afirmativa, Machado et al. (2007) observaram que, em rotação lavoura-pastagem com média de três anos, havia de 5 a $10 \mathrm{t} \mathrm{ha}^{-1}$ de matéria seca de raízes de $U$. brizantha, na camada de $0-0,20 \mathrm{~m}$ de solo, dependendo do manejo imposto. Santos et al. (2007) e Sarmento et al. (2008) constataram que mais da metade da massa de raízes de espécies de braquiária e de colonião concentra-se na camada de 0-0,10 m do solo. Esses sistemas produtivos, assim como os retratados nesta pesquisa, podem contribuir para a descompactação do solo, melhorando o ambiente para o desenvolvimento das culturas na área, em que os capins Xaraés e Tanzânia utilizados como plantas forrageiras se evidenciaram como excelentes opções para essa finalidade, tendo em vista que após o período de cultivo (E2 e E4) foram verificados os menores valores de Ds (Quadro 4).

Avaliando-se a resistência mecânica à penetração (RMP) durante o desenvolvimento das culturas, não se verificou diferença significativa para essa condição física do solo em razão das áreas de cultivo e espécies forrageiras utilizadas no período de entressafra, assim como entre as modalidades de semeadura (Quadro 5). Entretanto, a RMP foi influenciada pelas épocas de avaliação durante o período de condução do experimento; nas avaliações realizadas após a colheita da silagem nos dois anos agrícolas (E1 e E3), principalmente nas camadas mais superficiais, apresentaram os maiores valores, provavelmente por causa do tráfego de máquinas durante a operação de colheita da silagem.

Os resultados de RMP (Quadro 5), nas três profundidades avaliadas $(0-0,10 ; 0,10-0,20$; e 0,20-0,40 m), foram inferiores aos verificados antes da instalação do experimento (Quadro 1), demonstrando a viabilidade dos sistemas produtivos pela utilização das diferentes espécies em rotação de culturas em não resultar na compactação do solo, inclusive com efeito descompactador ao longo do tempo. De maneira geral, nas camadas superficiais (0-0,10 e 0,10-0,20 m), os valores de RMP foram maiores que os verificados na camada mais profunda (0,20-0,40 m), demonstrando que no SPD, em razão da menor mobilização do solo, a compactação superficial e a redução da MA são comuns.

Segundo Beutler et al. (2001), a resistência mecânica do solo à penetração aumenta com 
Quadro 5. Resistência mecânica à penetração (RMP) e umidade gravimétrica (UG) nas camadas de 0-0,10; 0,10-0,20; e 0,20-0,40 m de profundidade e estoque de carbono (EC) na camada de 0-0,20 m em sistemas de integração lavoura-pecuária de acordo com o sistema de manejo (consórcio ou sucessão) das culturas do milho e do sorgo com as espécies forrageiras capim-xaraés e capim-tanzânia e soja em sucessão, épocas de avaliação $\left(\mathrm{E}_{\mathrm{i}}\right)$ e valor-p do $\mathrm{F}$ para as interações entre os tratamentos, o sistema de manejo e época de avaliação

\begin{tabular}{|c|c|c|c|c|c|c|c|}
\hline Variável & RMP10 & RMP20 & RMP40 & UG10 & UG20 & UG40 & EC \\
\hline & & $\mathrm{MPa}$ & & & $\mathrm{kg} \mathrm{kg}^{-1}$ & & $\mathrm{tha}^{-1}$ \\
\hline \multicolumn{8}{|l|}{ Tratamento $(\mathrm{T})^{(1)}$} \\
\hline Milho/capim-xaraés/soja & 2,44 & 2,65 & 2,46 & 0,221 & 0,221 & 0,232 & 40,3 \\
\hline Sorgo/capim-xaraés/soja & 2,56 & 2,71 & 2,61 & 0,222 & 0,231 & 0,232 & 39,3 \\
\hline Milho/capim-tanzânia/soja & 2,60 & 2,75 & 2,48 & 0,219 & 0,224 & 0,233 & 40,8 \\
\hline Sorgo/capim-tanzânia/soja & 2,51 & 2,63 & 2,48 & 0,220 & 0,224 & 0,230 & 40,8 \\
\hline \multicolumn{8}{|l|}{ Sistema de manejo (S) } \\
\hline Consórcio & 2,51 & 2,68 & 2,54 & 0,225 & 0,221 & 0,231 & $39,1 \mathrm{~b}$ \\
\hline Sucessão & 2,54 & 2,69 & 2,48 & 0,220 & 0,224 & 0,232 & $41,3 \mathrm{a}$ \\
\hline \multicolumn{8}{|l|}{ Época $(E)^{(2)}$} \\
\hline E1 & $3,38 \mathrm{a}$ & $3,06 \mathrm{a}$ & $2,57 \mathrm{a}$ & 0,220 & 0,218 & 0,229 & $37,7 \mathrm{c}$ \\
\hline E2 & $1,65 \mathrm{c}$ & $2,21 \mathrm{c}$ & $2,36 \mathrm{c}$ & 0,226 & 0,220 & 0,231 & $40,1 \mathrm{~b}$ \\
\hline E3 & $3,09 \mathrm{a}$ & $2,72 \mathrm{~b}$ & $2,44 \mathrm{~b}$ & 0,224 & 0,222 & 0,225 & $42,3 \mathrm{a}$ \\
\hline E4 & $2,49 \mathrm{~b}$ & $2,75 \mathrm{~b}$ & $2,67 \mathrm{a}$ & 0,224 & 0,222 & 0,228 & $40,8 \mathrm{~b}$ \\
\hline E5 & $2,09 \mathrm{~b}$ & $2,68 \mathrm{~b}$ & $2,51 \mathrm{a}$ & 0,228 & 0,217 & 0,225 & $40,0 \mathrm{~b}$ \\
\hline \multicolumn{8}{|c|}{ Valor p para $\mathrm{F}$} \\
\hline $\mathrm{T} \times \mathrm{S}$ & 0,615 & 0,654 & 0,123 & 0,746 & 0,766 & 0,346 & 0,075 \\
\hline $\mathrm{T} \times \mathrm{E}$ & 0,331 & 0,811 & 0,372 & 0,315 & 0,366 & 0,100 & 0,392 \\
\hline $\mathrm{S} \times \mathrm{E}$ & 0,054 & 0,290 & 0,078 & 0,067 & 0,819 & 0,385 & 0,164 \\
\hline $\mathrm{T} \times \mathrm{S} \times \mathrm{E}$ & 0,302 & 0,993 & 0,185 & 0,572 & 0,186 & 0,089 & 0,961 \\
\hline CV (\%) & 24,00 & 19,65 & 14,42 & 8,88 & 7,53 & 6,05 & 9,53 \\
\hline
\end{tabular}

CV: coeficiente de variação. Médias seguidas de letras distintas nas colunas diferem entre si, pelo teste t de Student a $5 \%$. (1) Tratamentos: milho e sorgo solteiro ou consorciado com as forrageiras capim-xaraés ou capim-tanzânia para ensilagem; forrageiras no período de entressafra, em que estas foram implantadas por ocasião do consórcio com as culturas produtoras de grãos ou após a colheita dessas; e soja em sucessão. ${ }^{(2)}$ E1: 14/04/2011 e E3: 29/03/2012, após a colheita silagem de milho e sorgo no primeiro e segundo ano, respectivamente; E2: 29/10/2011 e E4: 22/10/2012, após o manejo das espécies forrageiras na entressafra no primeiro e segundo ano e E5: 03/04/2013, após a colheita da cultura da soja em sucessão.

a compactação do solo, sendo restritiva ao crescimento radicular das culturas quando esses valores se encontram acima da faixa entre 1,5 a 3,0 MPa. Dessa forma, a compactação do solo tem sido verificada pelo aumento da densidade e da relação entre macro e microporosidade. Entretanto, no SPD, a Ds pode diminuir com o tempo de adoção do sistema, o que, aliado aos sistemas de ILP, tem demonstrado melhoria física do solo em razão do aumento no teor de MOS, melhorando a estrutura do solo (Flores et al. 2007; Spera et al. 2010b; Chioderoli et al. 2012; Mendonça et al. 2013), comprovando a eficiência desses sistemas produtivos.

O estoque de carbono (EC) no solo, na camada de 0-0,20 m foi maior nas áreas de cultivo onde as espécies forrageiras foram implantadas em sucessão às culturas produtoras de grãos (Quadro 5). Entre as épocas de avaliação desse atributo durante a condução do experimento, houve aumento conforme os cultivos sucessivos, demonstrando a importância, mais uma vez, da rotação de culturas e do incremento de resíduos vegetais no solo, com intuito de melhorar a sua qualidade.

O uso e manejo inadequados do solo podem contribuir para a emissão de gases do efeito estufa, prejudicando o ambiente, trazendo problemas relacionados à sua sustentabilidade por causa da degradação da MOS, o que atinge negativamente os seus atributos físicos e químicos, bem como a biodiversidade. No entanto, práticas adequadas de manejo, que visam à manutenção ou mesmo ao acúmulo de $\mathrm{C}$ orgânico no sistema solo-planta podem atenuar os efeitos do aquecimento global (Carvalho et al., 2010). Dessa forma, torna-se importante enfatizar a importância da avaliação de sistemas produtivos como os apresentados por esta pesquisa, uma vez que esses baseiam-se nas premissas básicas para obtenção de uma agricultura sustentável na região de cerrado. 
Verificou-se que os valores para o estoque de carbono (EC) em todas as épocas de avaliação foram maiores que os obtidos no início da instalação do experimento, que se encontravam, em média, de $37,0 \mathrm{t} \mathrm{ha}^{-1}$ na camada de $0-0,20 \mathrm{~m}$ de profundidade, demonstrando a importância das práticas conservacionistas adotadas nesta pesquisa, como a rotação de culturas e o acúmulo de palhada na superfície do solo pelas plantas de cobertura no SPD, fazendo com que ocorresse incremento da quantidade de $\mathrm{C}$ no solo. Além dos benefícios às culturas, o sequestro de carbono no solo pode diminuir também a emissão de gases do efeito estufa, causando menor impacto ambiental na atividade em questão.

Dessa forma, os resíduos de matéria seca das plantas, além de proporcionar incremento no EC, permitem ainda recuperar os teores de MOS. Os resíduos vegetais são indispensáveis ainda para aumentar o tamanho e a estabilidade dos agregados e favorecer o controle da erosão e a resistência do solo à compactação. De acordo com Bayer et al. (2006), no SPD, torna-se necessária a entrada de cerca de 4 t ha $^{-1}$ ano $^{-1}$ de $\mathrm{C}$ ao sistema para compensar a quantidade perdida na decomposição dos resíduos orgânicos, o que dificilmente é obtido apenas com culturas anuais para que o sistema seja considerado eficiente e sustentável.

Sendo assim, o SPD pode ser considerado uma atividade com potencial para sequestrar C no solo. Siqueira Neto et al. (2009), avaliando o sequestro de $\mathrm{C}$ num Latossolo Vermelho distroférrico de textura argilosa em SPD, verificaram que os estoques de C no solo aumentaram com o tempo de implantação do SPD e que o aporte de resíduos culturais e a rotação de culturas com uso de leguminosas reduziram a mineralização da matéria orgânica, o que favoreceu o acúmulo de $\mathrm{C}$ no solo. Do mesmo modo, Costa et al. (2008), avaliando o potencial de sistemas de preparo de solo e de culturas na conservação de $\mathrm{C}$ em um Argissolo Vermelho no sul do país, verificaram que o SPD, associado à inclusão de culturas com alta adição de resíduos vegetais ricos em $\mathrm{C} \mathrm{e} \mathrm{N}$, resultaram em balanço positivo de $\mathrm{C}$ no solo, resultados esses semelhantes aos verificados neste trabalho.

Em regiões de clima tropical, as condições climáticas favorecem a rápida decomposição da MOS, fazendo com que haja menor acúmulo de $\mathrm{C}$ em relação às regiões de clima temperado. Apesar dessa maior taxa de decomposição de MOS, os solos em regiões de clima tropical podem estocar aproximadamente $32 \%$ do total de C orgânico contido nos solos do planeta (Eswaran et al., 1993).

\section{CONCLUSÕES}

Os sistemas de produção na integração lavoura-pecuária com plantio direto, mesmo com alta exportação de nutrientes e tráfego de máquinas, foram eficientes para manutenção e até melhoria da fertilidade e dos estoques de carbono do solo.

Os sistemas de integração lavoura-pecuária, ao longo de três anos, promoveram redução da compactação refletindo no incremento da macroporosidade e porosidade total e diminuição da resistência mecânica a penetração e densidade do solo, nas camadas de 0-0,10 e 0,10-0,20 m.

\section{AGRADECIMENTOS}

À Fundação de Amparo à Pesquisa do Estado de São Paulo pela concessão de bolsa de doutorado à primeira autora e pelo apoio financeiro ao projeto (Processo n ${ }^{\circ}$ 2011/01057-0).

\section{REFERÊNCIAS}

Benett CCS, Buzetti S, Silva KS, Bergamaschine AF, Fabricio JA. Produtividade, composição bromatológica do capim-Marandu a fontes, doses de nitrogênio. Ci Agrotec. 2008;32:1629-36.

Bayer C, Lovato T, Dieckow J, Zanatta JA, Mielniczuk J. A method for estimating coefficients of soil organic matter dynamics based on long-term experiments. Soil Till Res. 2006;19:217-26.

Bernoux M, Arrouays D, Cerri CC, Bourennane H. Modeling vertical distribution carbon in Oxisols of the Western Brazilian Amazon (Rondônia). Soil Sci. 1998;163:941-51.

Beutler AN, Silva MLN, Curi N, Ferreira MM, Cruz JC, Perreira Filho IA. Resistência à penetração, permeabilidade de Latossolo Vermelho distrófico típico sob sistemas de manejo na Região dos Cerrados. R Bras Ci Solo. 2001;25:167-77.

Calonego JC, Foloni JSS, Rosolem CA. Lixiviação de potássio da palha de plantas de cobertura em diferentes estádios de senescência após a dessecação química. R Bras Ci Solo. 2005;29:99-108.

Carvalho JLN, Avanzi JC, Silva MLN, Mello CR, Cerri CEP. Potencial de sequestro de carbono em diferentes biomas do Brasil. R Bras Ci Solo. 2010;34:277-89.

Chioderoli CA, Mello LMM, Grigolli PJ, Furlani CEA, Silva JOR, Cesarin AL. Atributos físicos do solo, produtividade de soja em sistema de consórcio milho, braquiária. R Bras Eng Agríc Amb. 2012;16:37-43.

Companhia Nacional de Abastecimento - Conab. Séries históricas relativas às safras 1976/77 a 2012/2013 de área plantada, produtividade, produção [internet]. Brasília, DF; 2013 [acesso em 5 dez 2013]. Disponível em: http://www.conab.gov.br/ conteudos.php?a=1253et.

Costa FS, Bayer C, Zanatta JA, Mielniczuk J. Estoque de carbono orgânico no solo e missões de dióxido de carbono influenciadas por sistemas de manejo no sul do Brasil. R Bras Ci Solo. 2008;32:323-32.

d'Andréa AF, Silva MLN, Curi N, Guilherme, LRG. Estoque de carbono e nitrogênio e formas de nitrogênio mineral em um solo submetido a diferentes sistemas de manejo. Pesq Agropec Bras. 2004; 39:179-86. 
Empresa Brasileira de Pesquisa Agropecuária - Embrapa. Centro Nacional de Pesquisa de Solos. Manual de métodos de análise de solo. $2^{\text {a }}$.ed. rev. atual. Rio de Janeiro: 1997.

Eswaran H, van den Berg E, Reich P. Organic carbon in soils of the word. Soil Sci Soc Am J. 1993;57:192-4.

Ferreira DF. SISVAR: Sistema de análise de variância. Lavras: Universidade Federal de Lavras; 1999.

Ferreira EVO, Anghinoni I, Andrighetti MH, Martins AP, Carvalho PCF. Ciclagem, balanço de potássio, produtividade de soja na integração lavoura-pecuária sob semeadura direta. $\mathrm{R}$ Bras Ci Solo. 2011;35:161-9.

Flores JPC, Anghinoni I, Cassol LC, Carvalho PCF, Leite JGDB, Fraga TI. Atributos físicos do solo, rendimento de soja em sistema plantio direto em integração lavoura-pecuária com diferentes pressões de pastejo. R Bras Ci Solo. 2007;31:771-80.

Hamza MA, Anderson WK. Soil compaction in cropping systems: A review of the nature, causes and possible solutions. Soil Till Res. 2005;82:121-45.

Lanzanova ME, Nicoloso RS, Lovato T, Eltz FLF, Amado TJC, Reinert DJ. Atributos físicos do solo em sistema de integração lavoura pecuária sob plantio direto. $\mathrm{R}$ Bras Ci Solo. 2007;31:1131-40

Lopes MLT, Carvalho PCF, Anghinoni I, Santos DT, Aguinaga AAQ, Flores JPC, Moraes, A. Sistema de integração lavourapecuária: Efeito do manejo da altura em pastagem de aveia preta, azevém anual sobre o rendimento da cultura da soja. Ci Rural. 2009;39:1499-1506.

Lourente ERP, Mercante FM, Marchetti ME, Souza LCF, Souza CMA, Gonçalves MC, Silva MAG. Rotação de culturas, relações com atributos químicos, microbiológicos do solo, produtividade do milho. Semina: Ci Agron. 2010;31:829-42.

Machado LAZ, Fabrício AC, Assis PGG, Maraschin GE. Estrutura do dossel em pastagens de capim-marandu submetidas a quatro ofertas de lâminas foliares. Pesq Agropec Bras. 2007;42:1495-501.

Marchão RL, Balbino LC, Silva EM, Santos Junior JDG, Sá MAC, Vilela L, Becquer T. Qualidade física de um Latossolo Vermelho sob sistemas de integração lavoura pecuária no Cerrado. Pesq Agropec Bras. 2007;42:873-82.

Mendonça VZ, Mello LMM, Andreotti M, Pereira FCBL, Lima RC, Valério Filho WV, Yano EH. Avaliação dos atributos físicos do solo em consórcio de forrageiras, milho em sucessão com soja em região de cerrados. R Bras Ci Solo. 2013;37:251-9.

Neumann M, Ost PR, Pellegrini LG, Defaveri FJ. Comportamento de híbridos de milho (Zea mays), sorgo (Sorghum bicolor) para silagem na região centro-sul do Paraná. Amb Guarap. 2008;4:237-50.

Pariz CM, Andreotti M, Bergamaschine AF, Buzetti S, Costa NR, Cavallini MC. Produção, composição bromatológica, índice de clorofila de braquiárias após o consórcio com milho. Arch Zootec. 2011;60:1041-52.

Paziani SF, Duarte AP, Nussio LG, Gallo PB, Bittar CMM, Zopollatto M, Reco, PC. Características agronômicas, bromatológicas de híbridos de milho para produção de silagem. R Bras Zootec. 2009;38:411-7.
Raij B van, Andrade JC, Cantarella H, Quaggio JA. Análise química para avaliação da fertilidade de solos tropicais. Campinas: Instituto Agronômico de Campinas; 2001.

Raij B van, Cantarella H, Quaggio JA, Furlani AMC, editores. Recomendações de adubação, calagem para o estado de São Paulo. $2^{a}$ ed. Campinas: Instituto Agronômico de Campinas; 1996. (Boletim técnico, 100)

Ruedell J. A soja numa agricultura sustentável. In: Silva, MTB, editor A soja na rotação de culturas no plantio direto. Cruz Alta: Cooperativas dos Produtores de Trigo e Soja do Rio Grande do Sul; 1998. p.1-34

Santos, H.G, Jacomine PKT, Anjos LHC, Oliveira VA, Oliveira JB, Coelho MR, Lumbreras JF, Cunha TJF, editores. Sistema brasileiro de classificação de solos. $2^{\mathrm{a}}$ ed. Rio de Janeiro: Empresa Brasileira de Pesquisa Agropecuária; 2006.

Santos RSM, Oliveira IP, Morais RF, Urquiaga SC, Boddey RM, Alves BJR. Componentes da parte aérea, raízes de pastagens de Brachiaria spp em diferentes idades após a reforma, como indicadores de produtividade em ambiente de Cerrado. Pesq Agropec Trop. 2007:2:119-24

Santos HP, Spera ST, Tomm GO, Kochann RA, Ávila, A. Efeito de sistemas de manejo de solo, de rotação de culturas na fertilidade do solo, após vinte anos. Bragantia. 2008;67:441-54.

Santos HP, Fontaneli RS, Spera ST, Dreon G. Fertilidade, teor de matéria orgânica do solo em sistemas de produção com integração lavoura, pecuária sob plantio direto. R Bras Ci Agron. 2011;6:474-82.

Sarmento P, Rodrigues LRA, Lugão SMB, Cruz MCP, Campos FP, Ferreira ME, Oliveira RF. Sistema radicular do Panicum maximum Jacq. cv. IPR-86 Milênio adubado com nitrogênio, submetido à lotação rotacionada. R Bras Zootec. 2008;37:27-34.

Silveira PM, Stone LF. Teores de nutrientes, de matéria orgânica afetados pela rotação de culturas, sistemas de preparo do solo. $\mathrm{R}$ Bras Ci Solo. 2001;25:387-94.

Siqueira Neto M, Venzke Filho SP, Piccolo MC, Cerri CEP, Cerri CC. Rotação de culturas no sistema plantio direto, em Tibagi (PR). I - Sequestro de carbono no solo. R Bras Ci Solo. 2009;33:1013-22.

Spera ST, Santos HP, Fontaneli RS, Tomm GO. Integração lavoura, pecuária, os atributos físicos de solo manejado sob sistema plantio direto. R Bras Ci Solo. 2009;33:129-36.

Spera ST, Santos HP, Fontaneli RS, Tomm GO. Atributos físicos de um Hapludox em função de sistemas de produção integração lavoura-pecuária (ILP), sob plantio direto. Acta Sci Agron. 2010a; 32:37-44

Spera ST, Santos HP, Fontaneli RS, Tomm GO. Efeito de integração entre lavoura, pecuária, sob plantio direto em alguns atributos físicos do solo após dez anos. Bragantia. 2010b;69:695-704.

Stolf R. Teoria, teste experimental de fórmulas de transformação dos dados de penetrômetro de impacto em resistência do solo. $\mathrm{R}$ Bras Ci Solo. 1991;15:229-35.

Wendling B, Jucksch I, Mendonça ES, Neves JCL. Carbono orgânico estabilidade de agregados de um Latossolo Vermelho sob diferentes manejos. Pesq Agropec Bras. 2005;40:487-94. 